\title{
The Design and Development of the Land Management System in Dingzhuang Town Based on Spatial Data
}

\author{
Yusheng Liang ${ }^{1}$, Wenbin $\mathrm{Sun}^{1}$, Haiting Diao ${ }^{2}$, and Ying $\mathrm{Li}^{3}$ \\ ${ }^{1}$ School of Geoscience and Surveying Engineering, \\ China University of Mining and Technology, Beijing, China, 100083 \\ yusheng20002002@yahoo.com.cn \\ ${ }^{2}$ School of Information Science and Engineering, Shandong Agricultural University, \\ Tai' an, Shandong, China, 271018 \\ ${ }^{3}$ School of Foreign Languages Shandong Agricultural University, \\ Tai' an, Shandong, China, 271018
}

\begin{abstract}
Taking as an example the land resources management in Dingzhuang town, Guangrao county, Shandong province, this thesis makes sufficient investigation and demand analysis in accordance with the features of land resources management in villages and towns. It studied in details the main content of land resources management in villages and towns. On this basis, the thesis first makes a general design of the land resources management system in Dingzhuang town, and an in-depth investigation of the functions of every modules in the information system of land resources management in villages and towns, together with the necessary principles for the design of system interface. In the following steps, it establishes through research the spatial database and attribute database, along with the platform of the geographic information system of Dingzhuang town on the basis of the spatial data and attribute data of this town. On this platform, it uses the relevant data of Dingzhuang town land resources and groupware second development technology to research and develop the information system of land resources management in villages and towns. The basic functions of this system include land use planning, basic farmland management, the management of land for construction use, land survey, land registration and so on. Besides, it realizes the basic land management of each patch in the village and town level, as well as property search map and map search function.
\end{abstract}

Keywords: spatial data, land management, system design, basic farmland.

\section{Introduction}

In the 2007 government report, Premier Wen pointed out, "With regard to land, we shall not make uncorrectable historical mistakes which will in turn bring our descendants catastrophes. Therefore, we must hold to the red string - at least 1.8 billion mu of cultivated land." According to his remarks, the protection of cultivated land, especially basic farmland is highly relative to national grain safety, economic development, social stability and vital interests of the farmers. It is the primary task of the land resources management. In addition, according to The Decision of CPCCC on Several Major Problems Concerning Propelling the Reform and Development in Rural Areas passed by 
the Third Plenary Session of the seventeenth Central Committee in 2008, farmers have the right to circulate the contracting right in different ways. Thus how to standardize land circulation through effective mechanisms has become a new project for land management in rural areas. With the fast economic development and steady increase of the popularity, the contradictions between man and land will deteriorate. Thus, we must strengthen the land management of rural areas. As the traditional inquiry of informaton by hand and the inefficient management style of independent dealing by different departments cannot satisfy the requirement of the dynamic land resources management in rural areas, the informationalization of this management with modern measures and scientific, efficient administration is highly in need.

Land management information system is the technique and method for land planning, management quantificaton and rationalization together with quick inquiry, analysis and innovation of land information. It provides supplementary support for decision making. The land resources management system based on spatial data improves the traditional land management system through computer technologies, communications net, remote sensing, geographic information system, satellite positioning system and so on. It realizes functions like the spatial visual management of land resources and the real-time innovation of spatial dynamic data.

According to long-term investigation, some cities and counties have had land resources management system, nevertheless, such systems in villages and towns are far from satisfaction. Nowadays, the building of new-typed countryside is being systematically carried out. The establishment of an efficient comprehensive information service system in rural area land management plays an important role in promoting town and country unification management and the rational, efficient and organized use of land in villages and towns. Therefore, this thesis takes as an example the land resources management in Dingzhuang town, Guangrao county, Shandong province, and focuses on the research and development of spatial data-based information system of land resources management in villages and towns.

\section{Requirements Analysis and Module Design}

Dingzhuang town, Guangrao county is located within the Half-hour economic circle of Dongying municipality and Shengli oilfield. It covers an area of 363 square kilometers, having jurisdiction of 45 administrative villages with a population of 42 thousand people. In this town, there is 160 thousand mu farmland, 11.8 kilometers coastline, 53 thousand low-lying beach land and over 40 thousand mu fresh water and seawater cultivation. In 2008, the total output value of the town reached 965 million RMB, and the fiscal revenue reached 8.063 million RMB. The farmers' per capita net income was 5390 RMB.

In terms of the building of new-typed countryside, Dingzhuang town seized the chance of being the pilot site of this activity in Dongying municipality and carried out the construction in a steady way. According to the reality of this town, it is not industrial and mining area, nor a resident county with little collective income in villages and relatively weak financial resources. On this basis, Dingzhuang town formed a clear train of thought for construction in accordance with the twenty-word guiding principle of new village construction, that is "Do not pursue large scale or learn from the West blindly; do not pursue an impractical and overly ambitious goal; base the constructions on the reality; exert the advantages and avoid the weaknesses; advance in an overall way". 
The land management system in villages and towns mainly caters to land administrations in villages and towns, whose design philosophy is easy operation and convenient use and management. Moreover, for timely renewal of the management and the system, the users of the system are divided into common users and system administrator. Common users can search and download relative information, and search the attribute information of the maps and so on. The system administrator can maintain the system by entering administrator name and code. Based on field investigation and analysis, the land management information system in villages and towns includes six parts: land use and management, farmland protection and management, land registry management, land planning management, law enforcement and supervision of land, together with system maintenance. The structure of this system is illustrated in Figure 1.

Land-use module contains two sub modules: the management of land for foundation of houses; the management of construction land for township enterprises, common facilities and public welfare undertaking. Its functions include application procedures for relative laws and regulations; map search management for land of foundation houses; attribute search; measurement of area, length and so on.

Farmland protection management contains five sub modules: basic laws and regulations; fundamental introduction; basic farmland; land development and organization; farmland conversion and expropriation. It introduces relative laws and regulations; basic situation of farmland; feasibility report for land development and organization; relative laws for the procedures of land conversion and expropriation applications. In addition, this module provides a form of the area of basic farmland reserves and basic farmland figures for relative inquiry.

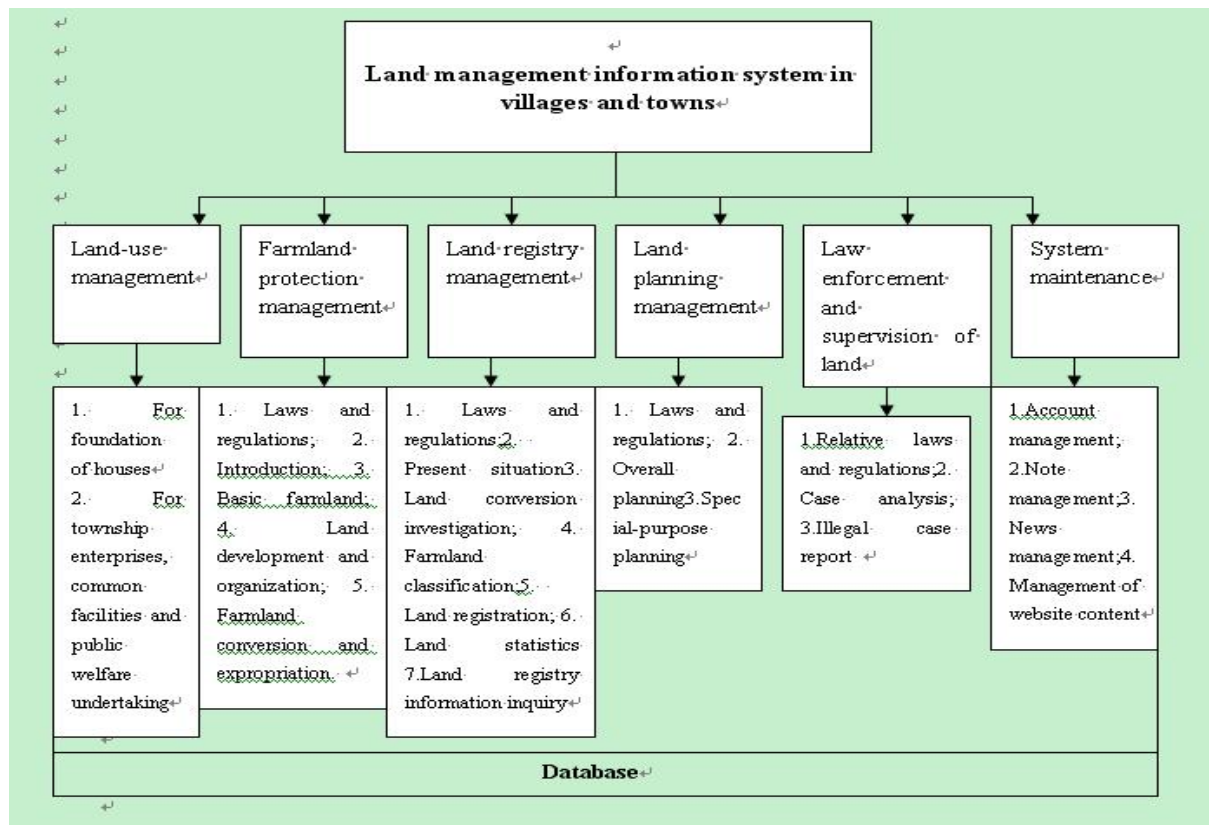

Fig. 1. Structure of land management information system in villages and towns 
Land registry management module contains seven sub modules: relative laws and regulations; the present situation of land use; land conversion investigation; farmland classification; land registration; land statistics and land registry information inquiry. This module provides the figures of present situation of land use, figures for soil classification, land registry figures and so on. It realizes functions like attribute inquiry and statistics as well as the measurement of area and length.

Land planning management contains three sub modules: relative laws and regulations; overall planning and special-purpose planning. It introduces relative laws and the overall planning aims of standard villages and towns, providing information for land planning administrations.

The module of law enforcement and supervision of land contains several sub modules: relative laws and regulations; case analysis; illegal case report and so on. It introduces details of the illegal cases and punishments, providing cases for the legal land use of land users.

System maintenance module contains four modules: account management; note management; news management and the management of website content, helping the administrator give timely renewal and maintenance.

\section{Main Functions of the System}

The information system of land resources management in villages and towns caters to the land administrations' need for the automation inside an office of land management, and helps to improve professionals' efficiency so as to manage large amounts of land use data effectively. This system provides scientific basis for the planning of land use in villages and towns, basic farmland protection and the decision-making people. The main functions include three aspects:

(1). An online unified management platform for land use information in villages and towns, which can deal with and reveal information visually, and can enable the end of users to get information through different ways. This can ensure the convenience, quickness and acuracy of information inquiry.

(2). An information renewal platform for land in villages and towns, which realizes a quick and convenient importing of land information. This can enable the administrators to import the latest land management information, which realizes the real time and synchronious innovation of land information.

(3). A complete use of all kinds of communication nets, which achieves the openness of land information in villages and towns; a reasonable direction in which the information flows; quick issue of land arrangement planning; timely report and solution of illegal land cases.

\section{Design, Research and Development of Main Interfaces}

There are two major principles for the design of users' interface: beautiful and accordance. In real design, the menus of the interface and special projects should be practical and classical, while all the menus, forms, controls and shortcut keys should be unified. Whether the interface is friendly or not determines the practicality of it and 
ease for use. The users of the land investigation information system are not all GIS professionals, thus the design of the users' interface should satisfy the need of all kinds of users, giving the system great applicability. This system is Windows Form application program designed by $\mathrm{C \#}$ which enables the computer users to use all kinds of Windows software without specific training through graphic interfaces. Besides, it is the standard that the program designers have to follow while designing Windows program interface, which reduces the burden of program designers and help concentrate their attention on solving and realizing the problems. C\#.Net, a kind of visual programming language, further simplifies the design work of the program interface. Only with few codes can we have the standard application program interface. However, if a person does not understand the design principles of Windows program interface, he could not design an interface that can both match general requirements and satisfy industry demands. The major principles for interface design are as follows:

(1). Convenient for operation. The system should reduce the frequency of operation and the memory burden of users. It should provide clues for relative operations and good help system, as well as setting hot keys for frequently conducted operations so as to realize the conciseness and efficiency of the interface functions.

(2). Reversibility of the operation. This is very useful for people without professional knowledge. The reversible actions can be single operation or a relatively independent operation formation.

(3). Unanimity of the interface style. For example the menus, windows, tools and buttons should be in accordance with each other. Same terms should be used in menus and help system. The dialog boxes should have the same style.

(4). Provide information feedback and simple error solution. There should be feedbacks for important operations of the operators, especially for the seldom used and most important operations. When there is an error, the system should detect the error and provide simple and clear solutions.

\subsection{Design, Research and Development of the General Interface of the System}

According to the above principles, this system borrows from the thought of "Modularity" and designs the system interface into a host interface and several sub-interfaces. A sub-interface is one function module, which can be started through host interface or started independently. All the sub-interfaces keep the same style. The host interface of the system is showed in Figure 2.

\subsection{Design, Research and Development of System Basic Modules}

System basic module mainly includes two functions: users' inquiry and administrators' updating the information and maintaining the system. The modules for users' inquiry include five modules: land use management; farmland protection management; land registry management; land planning management; law enforcement and supervision of land. Each module contains several small modules. The users can inquire certain information and download relative data and materials, as showed in Figure 3. Besides, the maps of standard villages and towns can be browsed and inquired in independent interfaces, as showed in Figure 4. 
This spatial information inquiry function contains four modules: layer demonstration; Hawkeye; attribute inquiry; inquiry outcome demonstration. In addition, there are other human-friendly functions like enlargement, shrinking, measurement, whole layer demonstration and so on. The first feature is that the users can inquire all kinds of land data information by clicking graphs, such as land plot basic information, land conversion information, basic geographic information and so on. The second feature is that users can inquire spatial graphic information by inputting conditions and also make inquiries by selecting land categories, the administration it belongs to and administrative region.

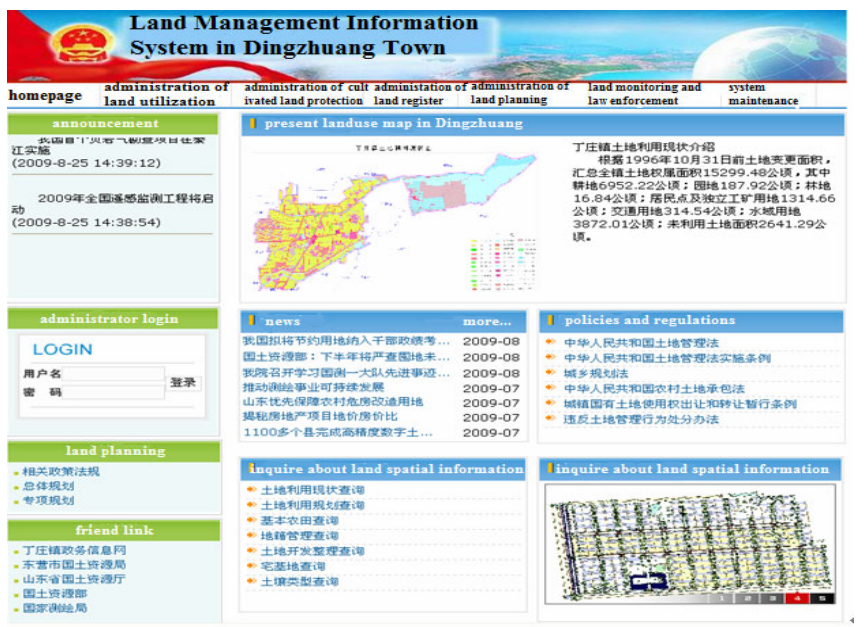

Fig. 2. Host interface of the system

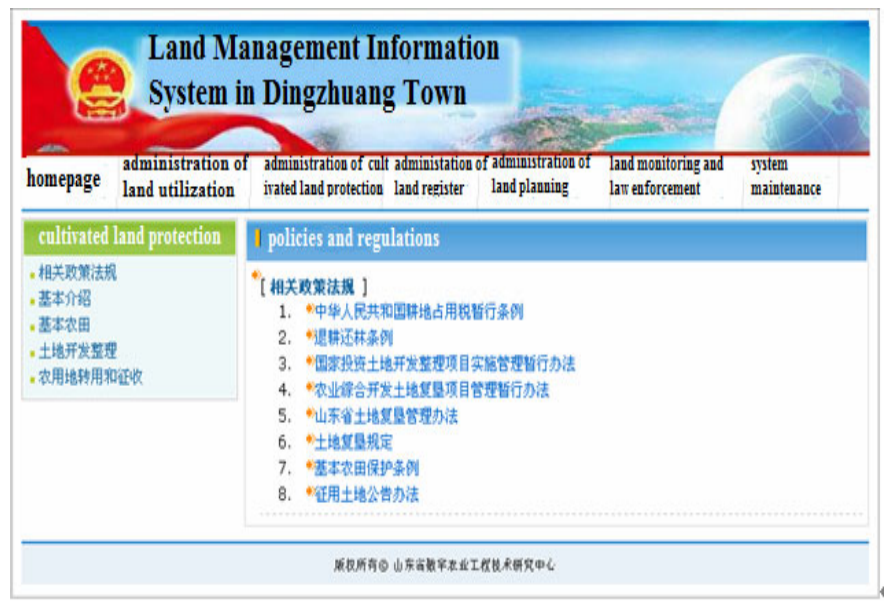

Fig. 3. Farmland protection interface 


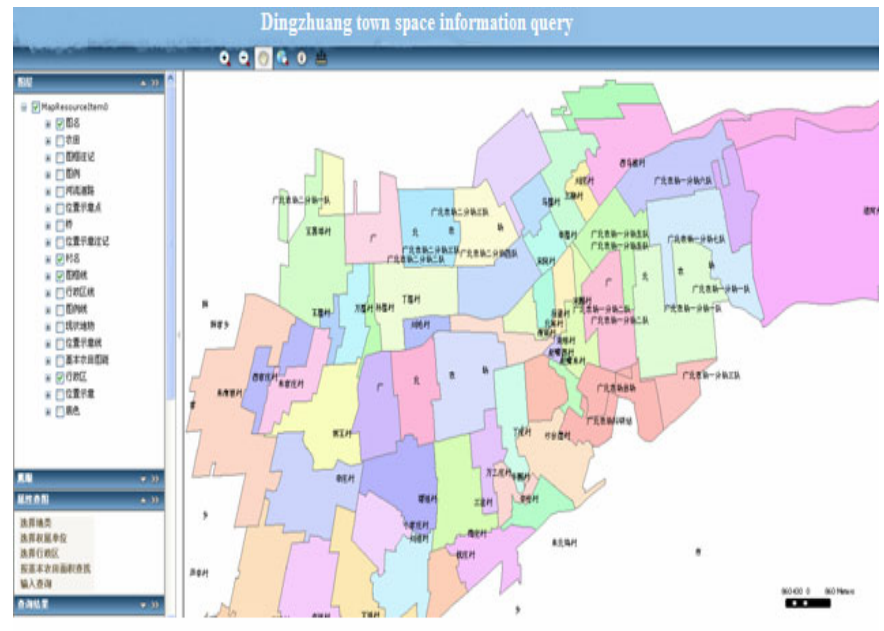

Fig. 4. The page of map browsing and inquiry

\subsection{Design, Research and Development of System Data Renewal and Maintenance Module}

The most important thing for establishing a system is not how to use it, but the renewal and maintenance of it. The data should be new, or it will be of no value but decorations. The main task of this system is to realize the renewal and maintenance of special subjects.

The renewal of data includes inputting the latest data into the system, correcting the existing data, supplement of needed data, deleting outdated data and so on. The maintenance mainly includes checks and corrections of integrity and cognation of data.

The renewal of data is large in amount and pressing in time. It requires regular renewal of some data. For example, annual land use and the change of right of ownership or other special projects. As to the change of some attribute data, for example, the change of the name of administrative villages, we only need to correct relative spatial information. These corrections can be made directly in layer operations instead of in the whole layer. In this way, the data redundancy created by the system is the lowest and difficulties in data management can be avoided, while the historical data are well preserved.

In this system, the administrator can log in administrator management module easily by inputting user name and code. This module contains account management, proclamation management, news management and website content management. Operations in different interfaces like corrections, addition and deletion can be conducted by merely clicking relative items. The interface is showed in Figure 5.

As the length of the thesis is limited, the design, research and development of other sub modules will not be illustrated. 


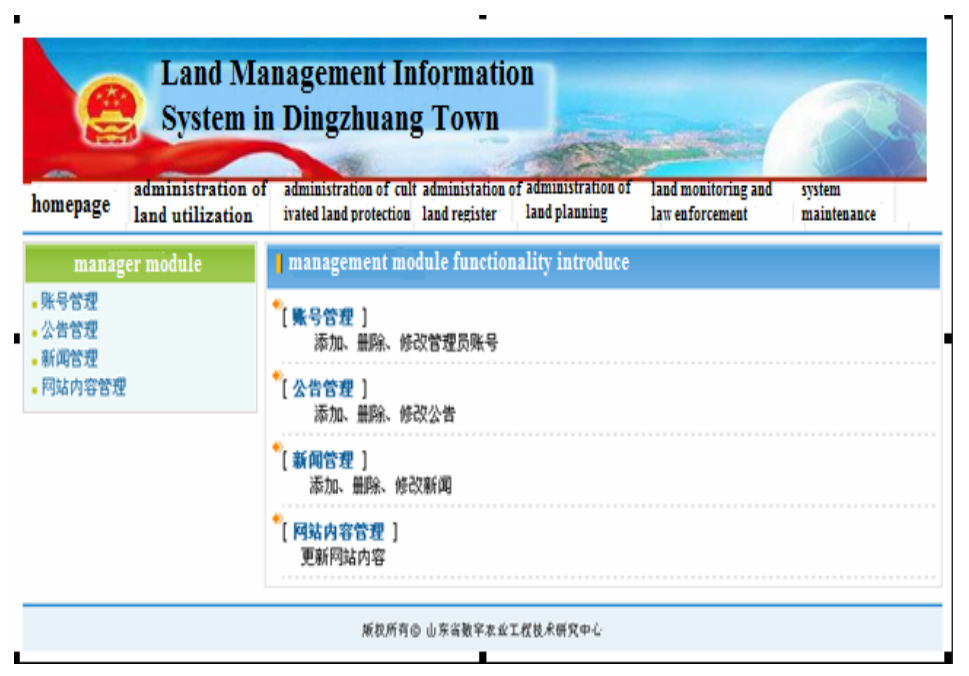

Fig. 5. System maintenance module interface

\section{Conclusion}

Based on complete use of mature spatial information technologies and serious research on land use and management, this thesis researched and developed seven modules including land conversion inquiry module and basic farmland management module. On this basis, it researched and developed the Dingzhuang town information system of land resources management based on spatial data. It provides land use and management with the real-time information and realizes functions like property search map, map search function, visual inquiry of land information and dynamic innovation of spatial graphic data. It raises the efficiency and level of primary level land management.

The system mainly has five features:

(1). Complete range of functions, flexible operations, easy manipulation and high practicality.

(2). Thorough use of mature visual technologies, multimedia technologies, database technologies and object-oriented technology. Good universality and maintainability.

(3). Information inquiry system based on geographic information system, which realizes graphic expression of spatial data information and the graphic expression and inquiry of relative land information.

(4). Remote renewal of present land use data and integration of electronic information provide public users with functions like online browsing, inquiry and issue of land development information.

(5). High integration and application of GIS and internet technologies greatly raises working efficiency and increases data reliability which better satisfies the needs of different departments. 
Three major innovation points:

(1). Independent research and development of database management system of Dingzhuang town, which realizes unified management of multi-source data and establishes service-oriented integrated module for heterogeneous data.

(2). Independent research and development of land management system of Dingzhuang town, which realizes basic farmland management of each patch, three generations of land conversion and dynamic management of land contract management right.

(3). Integrated and internet management of attribute data and spatial data in villages and towns, which realizes property search map and map search function and so on.

The research and development of the land management system in Dingzhuang town based on spatial data serve as a model in survey protection and service in building new-typed countryside around the country and propel the application of spatial information technologies in land management of villages and towns.

\section{References}

1. Chang, X., Nie, Y., Dong, X., et al.: Design of Land Use Planning Management Information System at County Level Based on WebGIS. Journal of Shandong Agricultural University 35(4), 589-592 (2004)

2. Xue, L., Li, L., Wang, L., et al.: The Exploitation of WebGIS Based on ArcGIS Server and Ajax. Agriculture Network Information 7, 24-27 (2008)

3. Zhu, D.: Land Management Information System. China Agricultural University Press (2002)

4. Zheng, X., Han, R.: Land Management Geographic Information System. Wuhan University Press, Wuhan (2008)

5. Mei, X., Yan, Y.: Visual C\# Internet Programming Technologies and Practice. Tsinghua University Press, Beijing (2008)

6. Liu, H.: Web-based Research and Development of House Property Management Information System, Xi'an University of Technology (2005)

7. Sun, J.: City Informationalization and City Basic Information System. The world press, Beijing (2001)

8. Fang, S., Zou, X., et al.: Researching Status and Developing Trend to Land Information System. Computer Engineering 29(20), 1-3 (2003)

9. Liu, J.: Foreign Land Survey Information System. Land \& Resources 8, 48-51 (2002)

10. Sun, J.: Land resources information systems to the research and establish. Energy press, Beijing (1986)

11. Cheng, Q.: The Establish and Updating Method Research of Land Utilize Database. Liaoning Engineering University Degree of Master Essay (2004)

12. Ma, J.: Construction and Application of Land Management Information System on Integration of City and Rural Area. Xi' an Technology College Degree of Master Essay (2002)

13. He, Y.: The Construction and Practice of the Spatial Data Management Model of Urban and Rural Integrative of the Modern Cadastral. Hehai University Degree of Master Essay (2005)

14. Dai, J.: The County Level of The Land System of Study and Application Databases. Land Resources Informatization (2003) 